\title{
Hybrid three-stage repair of mega aorta syndrome with the Lupiae technique
}

\author{
Nicola Troisi, MD, ${ }^{a}$ Samuele Bichi, MD, ${ }^{\mathrm{b}}$ Davide Patrini, MD, ${ }^{\mathrm{b}}$ Vincenzo Arena, MD, ${ }^{\mathrm{b}}$ Marco Setti, MD, ${ }^{\mathrm{a}}$ \\ Antonino Pitì, MD, ${ }^{\mathrm{c}}$ and Giampiero Esposito, $\mathrm{MD}^{\mathrm{b}}$
}

Objective: Open surgical replacement of the whole aorta in mega aorta syndrome remains a surgical challenge. We report our experience in the treatment of patients with mega aorta syndrome using a 3-stage hybrid repair.

Methods: From January 2006 to December 2011, 12 patients with mega aorta syndrome underwent total replacement of the aorta with a 3-stage hybrid repair, consisting of total replacement of the arch (first stage), retrograde revascularization of the visceral vessels (second stage), and deployment of an endograft (third stage). The intraoperative, early (30-day), and follow-up results were analyzed.

\begin{abstract}
Results: No intraoperative mortality occurred in any of the open or endovascular procedures. After the first stage, 1 patient died, resulting in a 30-day mortality of $8.3 \%$. After the second stage, the overall major morbidity was $27.3 \%$ ( 1 surgical revision and 2 temporary dialysis treatments). After the third stage, no conversion or major complication was recorded. The overall mean follow-up period was 31.9 months (range, 1-60 months). One patient died at 10 months postoperatively, and another patient required adjunctive implantation of a stent graft for a type III endoleak. At 3 years, the estimated survival, freedom from any device-related reinterventions, and freedom from type I endoleak was $83.3 \%, 77.9 \%$, and $100 \%$, respectively.
\end{abstract}

Conclusions: Our hybrid 3-stage approach seems to be effective in the treatment of mega aorta syndrome. The second stage was affected by non-negligible rates of perioperative complications. The overall mid-term results were encouraging, although a larger sample size with longer follow-up is needed to compare this technique with others. (J Thorac Cardiovasc Surg 2013;145:S171-7)

Multilevel aneurysmal aortic disease is a well-recognized condition. ${ }^{1}$ Sometimes, the whole aorta, from the coronary artery ostia to the iliac bifurcation, is involved in the aneurysmal disease. This condition has been described as mega aorta syndrome (MAS). ${ }^{2}$

Open surgical replacement of the whole aorta is a surgical challenge. The substitution of the aorta during a single operation has been described in only a few reports. ${ }^{2,3}$ The need to minimize the perioperative mortality and morbidity rates has encouraged many surgeons to investigate less-invasive techniques. Borst and colleagues ${ }^{4}$ first described the elephant trunk technique, consisting of a 2-stage open repair. Crawford and colleagues ${ }^{2}$ treated most of their patients with MAS using 2 to 3 open surgical steps. Recently, Shah and colleagues ${ }^{5}$ described a 2 -stage hybrid repair,

From the Department of Cardiovascular Disease, Section of Vascular Surgery, ${ }^{\text {a }}$ Section of Cardiac Surgery, ${ }^{\mathrm{b}}$ and Section of Interventional Cardiology, ${ }^{\mathrm{c}}$ Cliniche $\mathrm{Hu}-$ manitas Gavazzeni, Bergamo, Italy.

Disclosures: Drs Troisi, Bichi, Patrini, Arena, Setti, Pitì, and Esposito have nothing to disclose with regard to commercial support.

Presented at the American Association for Thoracic Surgery Aortic Surgery Symposium 2012, April 26-27, 2012, New York, NY.

Received for publication April 23, 2012; revisions received Aug 11, 2012; accepted for publication Nov 28, 2012

Address for reprints: Nicola Troisi, MD, Department of Cardiovascular Disease, Section of Vascular Surgery, Cliniche Humanitas Gavazzeni, Via Gavazzeni 21, Bergamo 24125, Italy (E-mail: nicola.troisi@alice.it).

$0022-5223 / \$ 36.00$

Copyright (c) 2013 by The American Association for Thoracic Surgery

http://dx.doi.org/10.1016/j.jtcvs.2012.11.057 consisting of a total arch replacement (stage I elephant trunk) followed by a hybrid open or endovascular repair of the thoracoabdominal segment.

We report our experience in the treatment of patients with MAS using a 3-stage hybrid repair, consisting of the total replacement of the arch (first stage), retrograde revascularization of the visceral vessels (second stage), and deployment of an endograft (third stage).

\section{PATIENTS AND METHODS \\ Patients}

From January 2006 to December 2011, we treated 96 patients with multilevel aneurysmal aortic disease. Of these, 12 patients with MAS underwent total replacement of the aorta with a 3-stage hybrid repair. All data concerning these interventions were prospectively collected in a dedicated database with about 80 fields, including demographic data, preoperative risk factors, clinical and diagnostic preoperative assessments, intraoperative features, and early (30-day) and follow-up results. All patients gave their written consent to the procedures, which were approved by the ethics committee. The first 2 stages were performed in the operating room, and the last endovascular stage was performed in the angiographic suite (Figure 1).

\section{First Stage}

The first stage has been described in a previous report. ${ }^{6}$ After induction of general anesthesia with endotracheal intubation, a transesophageal probe was inserted and transesophageal echocardiography monitoring was performed in all patients. Surgical repair was performed through a median sternotomy with the extension of the incision along the medial border of the left sternocleidomastoid muscle to better expose the supra-aortic vessels. After full intravenous anticoagulation, the brachiocephalic trunk was directly cannulated or exposed through a small right infraclavicular 


\section{Abbreviations and Acronyms \\ MAS = mega aorta syndrome \\ $\mathrm{TAAA}=$ thoracoabdominal aortic aneurysm}

incision using an 8-mm Dacron tube graft. Extracorporeal circulation and systemic cooling were started after cannulation of the right atrium with a standard 2-stage venous cannula, and the heart was vented through the right superior pulmonary vein. The left subclavian artery was then detached from the aortic arch and anastomosed end-to-end to an 8-mm Dacron tube graft connected to a separate low flow $(10 \mathrm{~mL} / \mathrm{kg} / \mathrm{min})$ perfusion line. Next, the ascending aorta was crossclamped. Myocardial protection was achieved using intracoronary infusion of cold $\left(5^{\circ} \mathrm{C}-8^{\circ} \mathrm{C}\right)$ crystalloid cardioplegia (Custodiol; Koehler Chemie, Alsbach-Haenlein, Germany). The proximal supracoronary aortic anastomosis was performed with 4-0 monofilament sutures using the Lupiae graft (Vascutek Terumo Inc, Inchinnan, Scotland), constructed with a standard cylindrical Dacron graft, with a trifurcated graft of different sizes $(10,10$, and $8 \mathrm{~mm})$ and another side branch of $10 \mathrm{~mm}$ coming off the main body of the prosthesis. ${ }^{7}$

After completion of the proximal anastomosis and achievement of moderate systemic hypothermia $\left(26^{\circ} \mathrm{C}-28^{\circ} \mathrm{C}\right)$, distal aortic flow was discontinued, and selective antegrade cerebral protection was begun, with a flow rate of about $10 \mathrm{~mL} / \mathrm{kg} / \mathrm{min}$ to maintain an arterial pressure in the right radial artery of 40 to $60 \mathrm{~mm} \mathrm{Hg}$. The distal anastomosis was performed on the aortic arch, preferring the space between the left carotid artery and left subclavian artery, with 4-0 monofilament sutures. The aortic crossclamp was released, and perfusion of the heart and distal thoracic aorta was guaranteed by connecting the arterial line with the lateral 10-mm Dacron branch of the Lupiae graft. Next, the left carotid artery and thereafter the brachiocephalic trunk were anastomosed to the bovine trunk-like side branch ( 8 and $10 \mathrm{~mm}$, respectively) of the Lupiae graft. Finally, after rewarming and removing extracorporeal circulation, the 10-mm side lateral branch of the Lupiae graft used for arterial systemic perfusion was anastomosed to the Dacron graft used for selective perfusion of the left subclavian artery (Figure 2, A).

\section{Second Stage}

With the patient under general anesthesia and in the supine position, a midline laparotomy was performed. The abdominal aorta, common iliac arteries, and initial portion of the celiac trunk, superior mesenteric artery, and renal arteries were exposed. The Lupiae graft or a similar multibranched graft was used for visceral vessel debranching. After intravenous anticoagulation, the abdominal aorta was crossclamped and replaced using the main body of the multibranched Dacron graft, using 4-0 monofilament sutures (Figure 2, $B$ ).

The side branches were distally anastomosed to the visceral vessels in a retrograde manner. In all reconstructions, the visceral vessels were ligated proximally to prevent retrograde perfusion of the aneurysmal sac. For renal revascularization, diuresis was forced by systemic infusion of furosemide. During renal artery crossclamping, a continuous perfusion of approximately $500 \mathrm{~mL}$ of cold $\left(4^{\circ} \mathrm{C}\right)$ crystalloid lactated Ringer's solution was administered into the orifice of the renal artery to reduce the temperature of the kidney (to $15^{\circ} \mathrm{C}-18^{\circ} \mathrm{C}$ ). For celiac trunk revascularization, the graft was routed in front of the left renal vein behind the pancreas. The superior mesenteric artery was anastomosed in a lazy-C fashion to avoid kinking. In all cases, the inferior mesenteric artery was reimplanted. All visceral anastomoses were performed in an end-to-side fashion (with the exception of the celiac trunk, which was anastomosed end-to-end) using 5-0 monofilament sutures. A final sequential declamping was performed. The grafts were then covered with retroperitoneum whenever possible.

\section{Third Stage}

The endovascular step was performed with the patient under locoregional anesthesia. One of the common femoral arteries was surgically exposed. The contralateral femoral artery was cannulated with a percutaneous puncture. The first step consisted of positioning a 0.035 -in. guidewire (Terumo, Terumo Medical Corp, Tokyo, Japan) for the insertion of a 5F short sheath using the percutaneous approach. Next, a $5 \mathrm{~F}$ pigtail catheter (Cordis Corp, Miami, Fla) was positioned immediately above the ostia of the coronary arteries. An intraoperative angiogram with nonionic contrast medium was performed to visualize the proximal radiopaque markers of the Lupiae graft.

Through the surgical access site, using a $260-\mathrm{cm}$ Lunderquist stiff wire (Cook Inc, Bloomington, Ind), the stent graft with its delivery system was advanced. The image intensifier was positioned at the base of the aortic arch to obtain the optimal angle for deploying the graft. When the proximal radiopaque markers of the Lupiae graft were visualized, delivery was performed. A completion angiogram was always performed to verify immediate technical success. Then the device was removed, and the other modules were deployed to cover the entire aorta up to the aortic anastomosis of the visceral debranching graft, using the radiopaque marker of the Lupiae graft. For adequate sealing of the stent graft, ballooning of the whole graft was performed in all cases with a Reliant balloon (Medtronic Cardiovascular, Santa Rosa, Calif; Figure 2, C).

\section{Follow-up and Statistical Analysis}

All patients routinely underwent computed tomography scan at each discharge. A computed tomography scan was then performed after the third stage at 6 and 12 months postoperatively and yearly thereafter. Statistical analysis was performed using SPSS, version 15.0, for Windows (SPSS Inc, Chicago, Ill). Continuous data are expressed as the mean \pm range. Categorical data are expressed as percentages. Follow-up data in terms of survival, freedom from any device-related reintervention, and freedom from type I endoleak were analyzed using life-table analysis (Kaplan-Meier test).

\section{RESULTS}

\section{Preoperative Clinical and Anatomic Features}

Patient demographic data and preoperative risk factors are summarized in Table 1 . The patients were predominantly men $(9 / 12,75 \%)$, with a mean age of 69.1 years (range, 28-81 years). According to the American Society of Anesthesiologists classification, before the first procedural stage, 4 patients $(33.3 \%)$ were considered in class IV. All patients had massive dilatation of the aorta; no dissections were present. One young patient had Marfan syndrome. The mean diameter of the aorta was $66.7 \mathrm{~mm}$ (range, $56-80 \mathrm{~mm}$ ).

The intraoperative technical data from each patient at each stage are listed in Table 2. During the first stage, 6 patients $(50 \%)$ underwent concomitant aortic valve repair, and 2 patients underwent concomitant coronary artery bypass grafting. After each procedure, the patients were admitted to the intensive care unit.

\section{Early Results}

No intraoperative mortality occurred in any of the open or endovascular procedures. After the first open surgical stage, 1 patient died of rupture of the descending thoracic aorta, for an overall perioperative 30-day mortality rate of $8.3 \%$ 

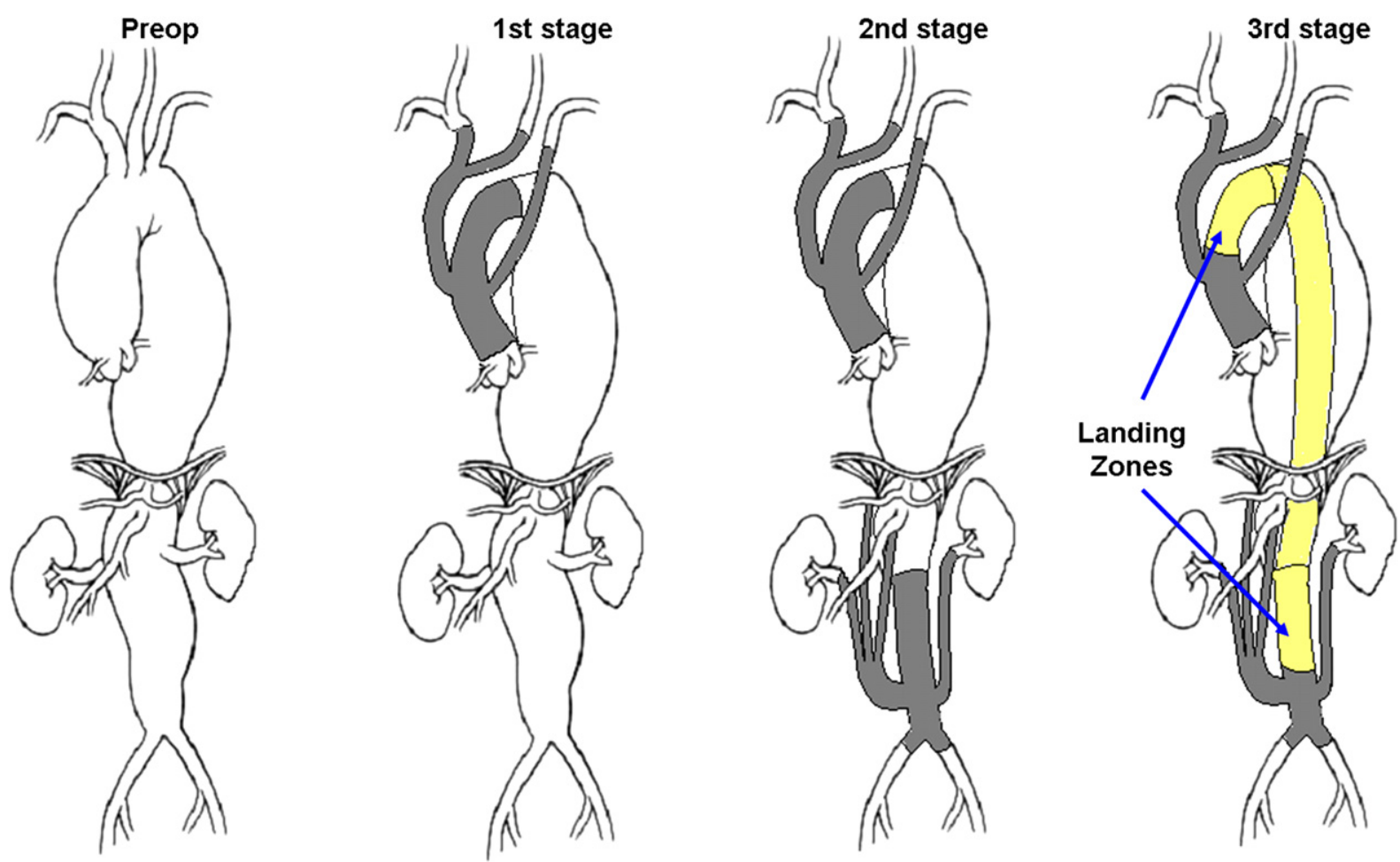

FIGURE 1. Scheme of hybrid 3-stage repair.

(1/12); no stroke, paraplegia, or reintervention occurred. The rate of major morbidity after the first stage was $8.3 \%$ ( 1 tracheostomy). The mean delay between the first and second stage was 69.5 days (range, 49-83 days).

After the second stage, no perioperative death occurred, but 1 patient required surgical revision for massive bleeding, and 2 patients required temporary dialysis for acute renal failure. The overall major morbidity rate was $27.3 \%$ (3/11). The mean delay between the second and third stage was 52.1 days (range, 38-61 days).

After the third endovascular stage, no surgical conversion or major complication was recorded. Four patients (36.4\%) developed a postimplantation syndrome. The computed tomography scan at discharge showed the absence of migration or type I/III endoleak in all patients.

\section{Follow-up Results}

Follow-up data were available for all patients, with an overall mean duration of 31.9 months (range, 1-60 months). The follow-up results are summarized in Table 2.

One patient died at 10 months postoperatively of acute myocardial infarction. During the follow-up period, no stroke, paraplegia, conversion to open repair, type I endoleak, or graft migration occurred. No patient required lifelong permanent dialysis. All supra-aortic branches were patent, and 1 asymptomatic occlusion of a renal branch occurred. In 1 patient, adjunctive implantation of a stent graft was necessary to correct a type III endoleak. One patient developed a median abdominal hernia that was surgically treated at 8 months.

At 3 years, the estimated survival, freedom from any device-related reintervention, and freedom from type I endoleak was $83.3 \%, 77.9 \%$, and $100 \%$, respectively (Figure 3). Univariate analysis demonstrated that none of the pre- or intraoperative factors significantly affected the 2-year rates of survival, freedom from any device-related reintervention, or freedom from type I endoleak.

\section{DISCUSSION}

The natural history of aortic aneurysms, regardless of etiology and location, is eventual rupture. Studies from the 1970s and 1980s showed that death occurred within 5 years in more than $75 \%$ of cases. ${ }^{8-10}$ A recent study conducted in the modern era demonstrated that $55 \%$ of patients with a thoracoabdominal aortic aneurysm (TAAA) and considered unfit for surgery had died within 1 year. ${ }^{11}$

MAS is a rare condition, and no study of its natural history has been published. MAS should be considered a serious life-threatening condition, and treatment within a short time from the diagnosis is mandatory.

The total replacement of the aorta in 1 step is a prohibitive surgical challenge. Thus, patients with MAS must undergo at least 2 procedures: the first to treat the aortic arch and the descending thoracic aorta, and the second to treat the 


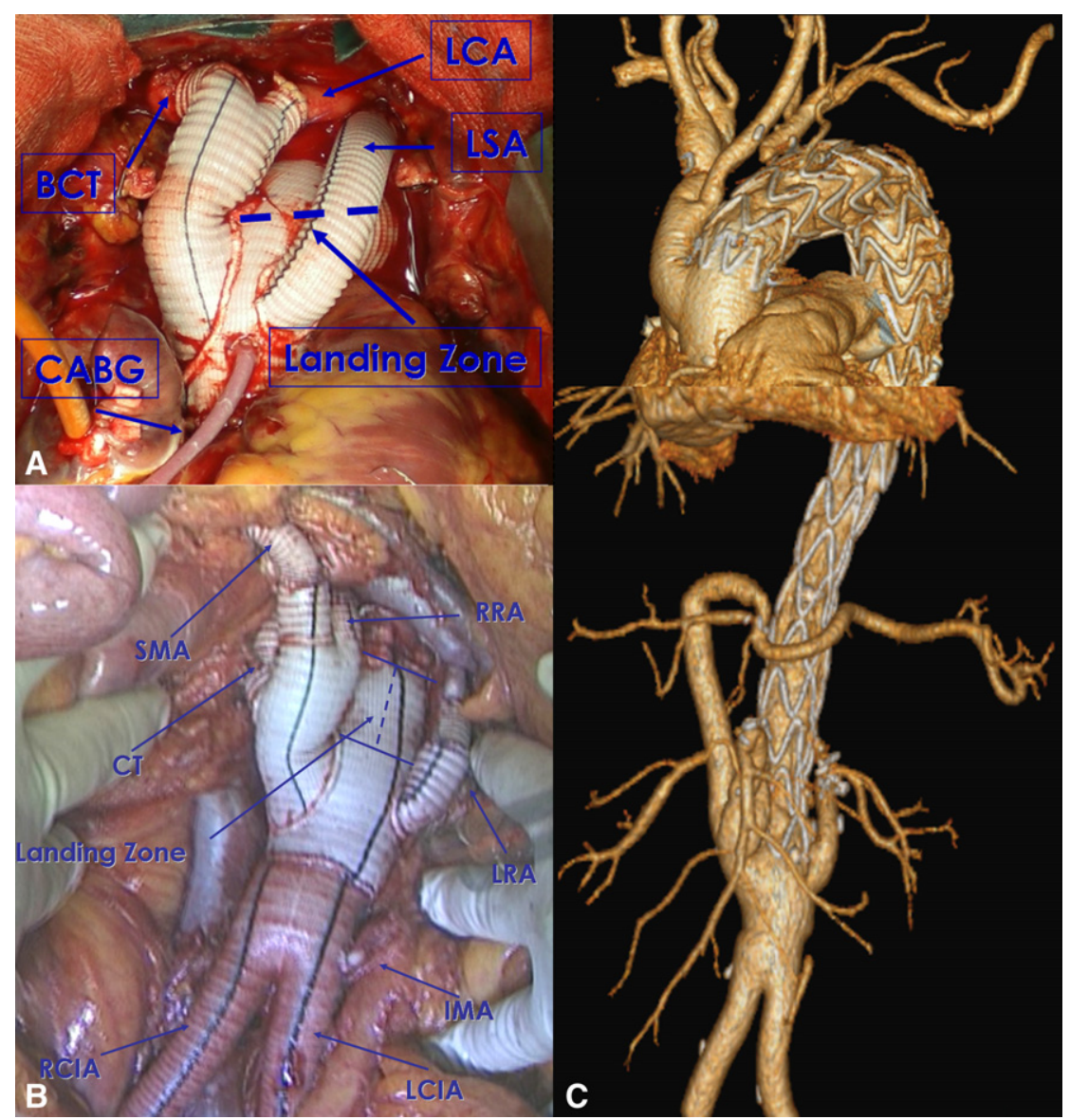

FIGURE 2. Intraoperative features (A, first stage; and B, second stage) and (C) computed tomography scan at discharge (third stage). BCT, Brachiocephalic trunk; $C A B G$, coronary artery bypass grafting; $L C A$, left common carotid artery; $L S A$, left subclavian artery; $S M A$, superior mesenteric artery; $C T$, celiac trunk; $R R A$, right renal artery; $L R A$, left renal artery; IMA, inferior mesenteric artery; $R C I A$, right common iliac artery; $L C I A$, left common iliac artery.

thoracoabdominal aortic tract. Borst and colleagues ${ }^{4}$ in 1983 significantly changed the traditional surgical approach to the treatment of patients with aneurysms involving both the ascending and the descending aortic segments at the same time. These investigators introduced the elephant trunk technique, which involves leaving a segment of Dacron prosthesis in the descending aorta during the first stage, making replacement of the aneurysmal descending aorta far easier in the second stage. A recent meta-analysis ${ }^{12}$ showed that the conventional elephant trunk technique resulted in in-hospital mortality of about $10 \%$ throughout 27 years of experience. Furthermore, this technique was accompanied by a non-negligible rate of stroke and spinal cord ischemia (4.6\% and $2 \%$, respectively).

Because of the need to minimize the operative risks, several investigators investigated the applicability of endovascular techniques for the treatment of the aortic arch and descending thoracic aorta. ${ }^{13-18}$ The single-stage frozen elephant trunk technique seemed to reduce the in-hospital mortality $(6.4 \%)$, even if the risk of stroke remained the same $(5 \%)$, with an increase in the risk of spinal cord ischemia. $^{12,16}$ In addition, total aortic arch debranching with subsequent standard endovascular exclusion did not reduce the overall in-hospital mortality $(8.3 \%)$ and maintained similar results in terms of stroke $(5.8 \%)$ and spinal cord ischemia $(1.6 \%) .{ }^{12}$ Thus, the results of novel open or endovascular techniques in the treatment of aneurysms involving the aortic arch and descending thoracic aorta appear contradictory.

With regard to the thoracoabdominal aortic segment, contemporary series showed that open repair can be performed with satisfactory results in centers of excellence. ${ }^{19,20}$ Moreover, Wong and colleagues ${ }^{21}$ demonstrated that the results obtained in the patients treated in more recent years are respectable $(7.9 \%$ mortality and $2.6 \%$ paraplegia), even when the outcomes were compared with those obtained with the emerging novel techniques (endovascular and hybrid).

The need to reduce the perioperative risks induced many to investigate less-invasive techniques. Total endovascular repair with fenestrated and branched devices represents an innovative technique to treat TAAAs. However, it requires 
TABLE 1. Demographic data and risk factors

\begin{tabular}{lc}
\hline \multicolumn{1}{c}{ Variable } & Value \\
\hline Gender & \\
Male & $9(75)$ \\
Female & $3(25)$ \\
Age (y) & \\
$\quad$ Mean & 69.1 \\
Range & $28-81$ \\
Smoking & $9(75)$ \\
Hypertension & $11(91.7)$ \\
Hypercholesterolemia & $4(33.3)$ \\
Diabetes mellitus & $3(25)$ \\
COPD & $8(66.7)$ \\
Chronic renal failure & $2(16.7)$ \\
Cerebrovascular disease & $1(8.3)$ \\
Coronary artery disease & $7(58.3)$ \\
Congestive heart failure & $4(33.3)$ \\
Severe aortic regurgitation & $6(50)$ \\
Chest/abdominal pain & $2(16.7)$ \\
\hline
\end{tabular}

COPD, Chronic obstructive pulmonary disease.

great expertise, and places with great experience are limited to a few centers worldwide. A recent review ${ }^{22}$ reported that the overall 30-day mortality in 155 patients with TAAAs included in their analysis was $7.1 \%$. Furthermore, the rate of permanent paraplegia or paraparesis was $3.2 \%$. These data are comparable, but not superior, to those obtained with open surgical repair performed in centers of excellence. ${ }^{18-20}$ In addition, the incidence of late complications requiring a secondary procedure was not negligible $(26.2 \%$ at a mean follow-up of 25 months). ${ }^{23}$

Hybrid 2-stage open or endovascular treatment of TAAAs was a recent alternative approach, consisting of the retrograde revascularization of the visceral vessels through a midline laparotomy, with the subsequent deployment of a standard endograft. Most published reports regarding this technique have been case series, with ambiguous results. A recent meta-analysis ${ }^{24}$ showed that repair of thoracoabdominal pathologic features using hybrid procedures in patients who are poor surgical candidates is still associated with significant morbidity and mortality. In particular, the pooled estimate for 30-day mortality was $12.8 \%$, and the pooled rate for irreversible paraplegia was $4.5 \%$. Thus, also in this field, the results of innovative, less-invasive techniques seem to be contradictory.

Our novel technique offers some news in the variegated scenario of aortic treatment. It is a 3-stage repair that offers the possibility of treating the whole aorta (from the coronary ostia to the aortic bifurcation), combining open and endovascular techniques. Replacement of the aorta was distributed within about 3 months. In our experience, no spinal cord injury occurred, despite sacrifice of all intercostal and lumbar vessels. We would attribute this to the fact that the segmental artery sacrifice was staged, eliminating the lumbar vessels first at the second stage and then, after a delay, the intercostal arteries at the third stage. This has been previously reported by Etz and colleagues ${ }^{25}$ in their experience with the 2-stage procedure and in laboratory studies demonstrating recovery of spinal perfusion pressures within a few days of segmental vessel occlusion ${ }^{26}$ or absence of spinal cord injury after staged hybrid lumbar and intercostal sacrifice. ${ }^{27}$

Moreover, our technique uses an innovative multibranched prosthesis (Lupiae graft) designed to obtain an optimal Dacron landing zone of 4 to $6 \mathrm{~cm}$ in both the ascending aorta (proximal) and the abdominal aorta (distal), for easier endovascular stent graft deployment. The

TABLE 2. Intraoperative, early (30-day), and follow-up results

\begin{tabular}{|c|c|c|c|c|c|c|c|c|c|c|}
\hline \multirow[b]{2}{*}{$\begin{array}{l}\text { Pt. } \\
\text { no. }\end{array}$} & \multicolumn{3}{|c|}{ First stage } & \multicolumn{3}{|c|}{ Second stage } & \multicolumn{2}{|c|}{ Third stage } & \multicolumn{2}{|c|}{ Follow-up } \\
\hline & $\begin{array}{c}\text { Branches } \\
\text { (n) }\end{array}$ & Complications & $\begin{array}{c}\text { Interval } \\
\text { between } \\
\text { stages (d) }\end{array}$ & $\begin{array}{c}\text { Branches } \\
\text { (n) }\end{array}$ & Complications & $\begin{array}{c}\text { Interval } \\
\text { between } \\
\text { stages (d) }\end{array}$ & Endograft & Complications & $\begin{array}{c}\text { Duration } \\
\text { (mo) }\end{array}$ & Complications \\
\hline 1 & 4 & Tracheostomy & 72 & 4 & Temporary dialysis & 57 & Valiant* & & 60 & \\
\hline 2 & 4 & & 68 & 3 & & 61 & Valiant & & 60 & \\
\hline 3 & 4 & & 70 & 4 & & 46 & Valiant & & 60 & \\
\hline 4 & 4 & Death & - & - & - & - & - & - & 1 & Death \\
\hline 5 & 4 & & 71 & 2 & & 60 & Valiant & & 48 & \\
\hline 6 & 4 & & 83 & 4 & $\begin{array}{l}\text { Surgical revision for } \\
\text { bleeding }\end{array}$ & 45 & Valiant & & 36 & Type III endoleak \\
\hline 7 & 4 & & 49 & 2 & & 38 & Valiant & & 36 & \\
\hline 8 & 4 & & 81 & 4 & & 53 & Valiant & & 24 & \\
\hline 9 & 4 & & 73 & 4 & & 52 & Valiant & & 10 & Death \\
\hline 10 & 4 & & 61 & 4 & & 47 & E-Vita $\dagger$ & & 24 & Abdominal hernia \\
\hline 11 & 4 & & 66 & 4 & & 60 & Valiant & & 12 & \\
\hline 12 & 4 & & 71 & 4 & Temporary dialysis & 54 & Valiant & & 12 & $\begin{array}{l}\text { Renal branch } \\
\text { occlusion }\end{array}$ \\
\hline
\end{tabular}

Pt. No., Patient number. *Valiant is a trademark of Medtronic Cardiovascular (Santa Rosa, Calif). †E-Vita is a trademark of Jotec (Hechingen, Germany). 

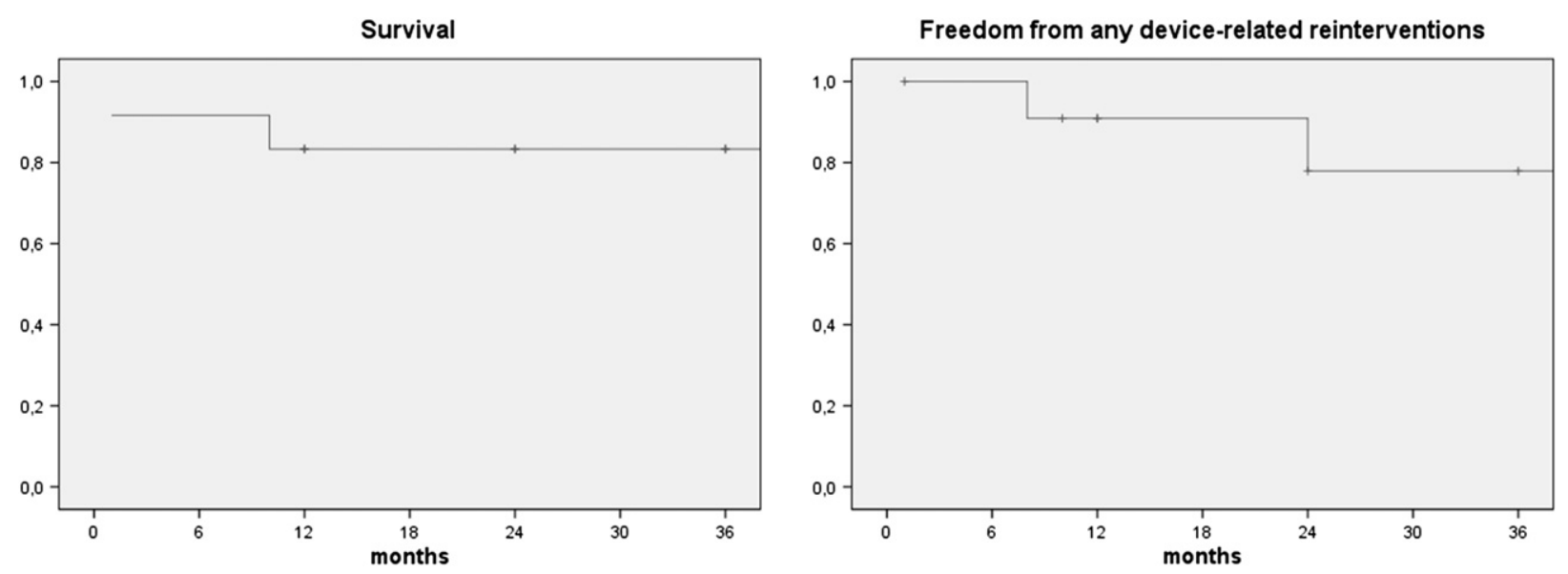

FIGURE 3. Estimated 3-year life-table analyses (Kaplan-Meier test).

presence of radiopaque markers facilitates the release of the stent graft in the safe area of the Dacron graft, minimizing the risk of type I endoleak. In the present series, no patient experienced a type $\mathrm{I}(\mathrm{a} / \mathrm{b})$ endoleak during follow-up.

The first stage of our procedure appeared to be safe and effective, and the results in terms of mortality $(8.3 \%)$ were comparable with those obtained with other techniques. In contrast, the second stage appeared to be affected by more frequent complications, although our outcomes seemed to be better than those reported in published studies of hybrid treatment of TAAA. Finally, the third stage seemed to be safe. Only 1 patient developed a type III endoleak during follow-up (separation between 2 modules), probably related to the excessive length of the endograft.

\section{CONCLUSIONS}

Our hybrid 3-stage approach seems to be effective in the treatment of MAS. The second stage was affected by nonnegligible rates of perioperative complications. The overall midterm results were encouraging, although a larger sample size with longer follow-up is needed to compare this technique with others.

\section{References}

1. Crawford ES, Cohen ES. Aortic aneurysm: a multifocal disease. Presidential address. Arch Surg. 1982;117:1393-400.

2. Crawford ES, Coselli JS, Svensson LG, Safi HJ, Hess KR. Diffuse aneurysmal disease (chronic aortic dissection, Marfan, and mega aorta syndromes) and multiple aneurysm: treatment by subtotal and total aortic replacement emphasizing the elephant trunk operation. Ann Surg. 1990;211:521-37.

3. Svennson LG, Shahian DM, Davis FG, Entrup MH, Kimmel WA, McGrath DM, et al. Replacement of entire aorta from aortic valve to bifurcation during one operation. Ann Thorac Surg. 1994;58:1164-6.

4. Borst HG, Walterbusch G, Schaps D. Extensive aortic replacement using "elephant trunk" prosthesis. Thorac Cardiovasc Surg. 1983;31:37-40.

5. Shah AA, Bhattacharya SD, McCann RL, Hughes GC. Pan-aortic hybrid treatment of mega-aorta syndrome. J Vasc Surg. 2011;53:1398-401.

6. Marullo AG, Bichi S, Pennetta RA, Di Matteo G, Cricco AM, Specchia L, et al. Hybrid aortic debranching with staged endovascular completion in DeBakey type I aortic dissection. Ann Thorac Surg. 2010;90:1847-53.
7. Esposito G, Cappabianca G, Contegiacomo G, Labriola G, Gallo N, Labriola C. Hybrid repair of thoracic and thoracoabdominal aortic aneurysms (mega aortic syndrome) with Lupiae technique. Innovations (Phila). 2011;6:366-72.

8. Szilagyi DE, Elliott JP, Smith RF. Clinical fate of the patient with asymptomatic abdominal aortic aneurysm and unfit for surgical treatment. Arch Surg. 1972;104: 600-6.

9. Pressler V, McNamara JJ. Thoracic aortic aneurysm: natural history and treatment. J Thorac Cardiovasc Surg. 1980;79:489-98.

10. Crawford ES, DeNatale RW. Thoracoabdominal aortic aneurysm: observations regarding the natural course of the disease. J Vasc Surg. 1986;3:578-82.

11. Hansen PA, Richards JM, Tambyraja AL, Khan LR, Chalmers RT. Natural history of thoraco-abdominal aneurysm in high-risk patients. Eur J Vasc Endovasc Surg. 2010;39:266-70.

12. Ius F, Hagl C, Haverich A, Pichlmaier M. Elephant trunk procedure 27 years after Borst: what remains and what is new? Eur J Cardiothorac Surg. 2011;40: $1-12$.

13. Mizuno T, Toyama M, Tabuchi N, Wu H, Sunamori M. Stented elephant trunk procedure combined with ascending aorta and arch replacement for acute type A aortic dissection. Eur J Cardiothorac Surg. 2002;22:504-9.

14. Shimamura K, Kuratani T, Matsumiya G, Kato M, Shirakawa Y, Takano H, et al. Long-term results of the open stent-grafting technique for extended aortic arch disease. J Thorac Cardiovasc Surg. 2008;135:1261-9.

15. Di Bartolomeo R, Di Marco L, Armaro A, Marsili D, Leone A, Pilato E, et al. Treatment of complex disease of the thoracic aorta: the frozen elephant trunk technique with the E-Vita open prosthesis. Eur J Cardiothorac Surg. 2009;35: 671-6.

16. Miyairi T, Kotsuka Y, Ezure M, Ono M, Morota T, Kubota H, et al. Open stentgrafting for aortic arch aneurysm is associated with increased risk of paraplegia. Ann Thorac Surg. 2002;74:83-9.

17. Inoue K, Hosokawa H, Iwase T, Sato M, Yoshida Y, Ueno K, et al. Aortic arch reconstruction by transluminally placed endovascular branched stent graft. Circulation. 1999; 100(suppl II):II316-21.

18. Kurimoto Y, Kawaharada N, Ito T, Baba T, Ohori S, Watanabe A, Asai Y, et al. Less-invasive management of left subclavian artery in stent-grafting for distal aortic arch disease. Interact Cardiovasc Thorac Surg. 2009;8:548-52.

19. Coselli JS, Bozinovski J, LeMaire SA. Open surgical repair of 2286 thoracoabdominal aortic aneurysms. Ann Thorac Surg. 2007;83:S862-4.

20. Conrad MF, Crawford RS, Davison JK, Cambria RP. Thoracoabdominal aneurysm repair: a 20-year experience. Ann Thorac Surg. 2007;83:S856-61.

21. Wong DR, Parenti JL, Green SY, Chowdhary V, Liao JM, Zarda S, et al. Open repair of thoracoabdominal aortic aneurysm in the modern surgical era: contemporary outcomes in 509 patients. J Am Coll Surg. 2011;212:569-81.

22. Bakoyiannis CN, Economopoulos KP, Georgopoulos S, Klonaris C, Shialarou M, Kafeza M, et al. Fenestrated and branched endografts for the treatment of thoracoabdominal aortic aneurysms: a systematic review. J Endovasc Ther. 2010; 17:201-9.

23. Troisi N, Donas KP, Austermann M, Tessarek J, Umscheid T, Torsello G. Secondary procedures after aortic aneurysm repair with fenestrated and branched endografts. J Endovasc Ther. 2011;18:146-53. 
24. Moulakakis KG, Mylonas SN, Avgerinos ED, Kaksis JD, Brunkwall J, Liapis CD. Hybrid open endovascular technique for aortic thoracoabdominal pathologies. Circulation. 2011;124:2670-80.

25. Etz CD, Zoli S, Mueller CS, Bodian CA, Di Luozzo G, Lazala R, et al. Staged repair significantly reduces paraplegia rate after extensive thoracoabdominal aortic aneurysm repair. J Thorac Cardiovasc Surg. 2010;139: 1464-72.
26. Etz CD, Homann TM, Plestis KA, Zhang N, Luehr M, Weisz DJ, et al. Spina cord perfusion after extensive segmental artery sacrifice: can paraplegia be prevented? Eur J Cardiothorac Surg. 2007;31:643-8.

27. Bischoff MS, Scheumann J, Brenner RM, Ladage D, Bodian CA, Kleinman G, et al. Staged approach prevents spinal cord injury in hybrid surgicalendovascular thoracoabdominal aortic aneurysm repair: an experimental model Ann Thorac Surg. 2011;92:138-46; discussion 146. 